\title{
Assimilative Modeling of Ionospheric Disturbances with FORMOSAT-3/COSMIC and Ground-Based GPS Measurements
}

\author{
Xiaoqing $\mathrm{Pi}^{*}$, Anthony J. Mannucci, Byron A. Iijima, Brian D. Wilson, Attila Komjathy, \\ Thomas F. Runge, and Vardan Akopian \\ Jet Propulsion Laboratory, California Institute of Technology, Pasadena, CA 91109, USA
}

Received 6 June 2007, accepted 4 January 2008

\begin{abstract}
The four-dimensional Global Assimilative Ionospheric Model (GAIM) is applied to a study of ionospheric disturbances. The investigation is focused on disturbance features, particularly in the altitude and latitude dimensions, at low latitudes during a geomagnetic storm on 7 August 2006, under solar minimum conditions. The modeling of storm-time ionospheric state (electron density) is conducted by assimilating an unprecedented volume of line-of-sight TEC data collected by the Global Positioning System (GPS) occultation receivers on board six FORMOSAT-3/COSMIC satellites and geodetic-quality GPS receivers at two hundred globally-distributed ground tracking stations. With a band-limited Kalman filter technique to update the ionospheric state, the assimilative modeling reveals a pronounced enhancement in the equatorial anomaly in the East Asia sector during dusk and evening hours. The disturbance characteristics, obtained by comparing with the quiet conditions prior to the storm also modeled in this study through data assimilation, include lifted F layer and reduced electron density in the equatorial region, enhanced density at the magnetically conjugate anomaly latitudes, and tilted feature of density increase towards higher altitudes at lower latitudes. The characteristics are attributed to the enhanced plasma fountain effect driven by an enhanced eastward zonal electric field. These results enable us to distinguish the storm-time electric field perturbations clearly from other sources during the storm. The possible origins of electric field perturbations are also discussed, including penetration of the magnetospheric electric field and wind dynamo disturbances.
\end{abstract}

Key words: Assimilative ionospheric modeling, GPS observation system, Ionospheric storm, Electric field perturbation

Citation: Pi, X., A. J. Mannucci, B. A. Iijima, B. D. Wilson, A. Komjathy, T. F. Runge, and V. Akopian, 2009: Assimilative modeling of ionospheric disturbances with FORMOSAT-3/COSMIC and ground-based GPS measurements. Terr. Atmos. Ocean. Sci., 20, 273-285, doi: 10.3319/TAO.2008.01.04.01(F3C)

\section{INTRODUCTION}

The recent development of assimilative ionospheric models marks a transition from first-principles or forward modeling to a new capability for specifying the Earth's ionospheric weather. A fundamental difficulty of the forward modeling approach is the specifications of the weather conditions of required model drivers, including the solar EUV radiation spectrum, electric field in the upper atmosphere that drives plasma convection, thermospheric composition and wind, and charged particle precipitation. In traditional modeling practice these drivers are provided either by estimates obtained from empirical models that characterize statistical patterns, or from the first principles physics-based models. The results of such modeling approaches often devi-

\footnotetext{
* Corresponding author

E-mail:Xiaoqing.Pi@jpl.nasa.gov
}

ate from the weather conditions due to the significant variability of the drivers. Assimilative models incorporate the first-principles models and optimization modules, allowing assimilation of measurements into the forward models and helping to bring the modeling in line with the weather conditions.

Several studies have been reported in the last few years, in which line-of-sight (LOS) total electron content (TEC) measured using Global Positioning System (GPS) receivers at ground-based stations are used as an assimilation data source to improve the modeling of volume electron density, or to estimate selected model drivers (e.g., Hajj et al. 2000, 2004; Rosen et al. 2001; Pi et al. 2003, 2004a, b; Schieless et al. 2004; Wang et al. 2004; Mandrake et al. 2005; Angling and Khattatov 2006; Jee et al. 2007). The modeling results of electron density are also integrated 
to obtain TEC either vertically or along the line-of-sight. The modeled TEC has been compared with several independent measurements, including vertical TEC along TOPEX and Jason-1 ocean altimeter orbit tracks, slant TEC along GPS observation links, and vertical TEC obtained from 2-dimensional (2D) global ionospheric maps (GIM) (e.g., Mandrake et al. 2005). All these comparisons show great improvement in modeling ionospheric weather, particularly for TEC.

It is worth pointing out that without physics-based ionospheric models, GPS TEC data have also been applied extensively in tomographic approaches in reconstructing $2 \mathrm{D}$ and 3D ionospheric electron densities (e.g., HernándezPajares et al. 1998; Mitchell et al. 1998; Yin et al. 2004; Garcia-Fernandez et al. 2005; Yin et al. 2006; Bust and Crowley 2007; Bust et al. 2007). For example, Yin et al. (2004) performed a time-dependent 3D tomographic imaging of middle-latitude ionospheric density using GPS data to study a severe storm that occurred during July 2000. A brief review of the involved approaches is given by Bust et al. (2007). A fundamental difference between these tomographic approaches and physics model based data assimilation is that the latter involves a state transition matrix that adjusts the ionospheric state from one time step to the next based on the model physics. In the tomographic approaches, no transition based on physics processes can be performed. Fundamentally, data assimilation based on a physics model has a potential to allow both correction of the ionospheric state and adjustment of the model drivers at the same time. Both capabilities are desirable in an assimilative ionospheric model. On the other hand, the tomographic approaches have advantages in reduced computational requirements and potentially simpler operations.

We now present a study of ionospheric disturbances during a geomagnetic storm using the 4D Global Assimilative Ionospheric Model (GAIM). The GAIM used in this study has been developed jointly at the University of Southern California and the Jet Propulsion Laboratory. The model development has involved reconstruction of a physics model to suit data assimilation requirements, and incorporation of optimization techniques including the 4-dimensional variational (4DVAR) approach and band-limited Kalman filter (BLKF) technique. In this study, only the BLKF approach with the GAIM physics model is used to perform the state prediction and transition. No model drivers are adjusted as in the 4DVAR approach. Thus corrections to the model predictions made through data assimilation are similar to that of the model-aided tomographic approach, except that the state transition is performed through the GAIM physics model. Thus the investigation is focused on ionospheric state disturbances under storm conditions, while possible dynamical processes during the storm will be discussed and interpreted by examining characteristics of the state variations.

Our model study is performed by assimilating TEC data obtained from GPS occultation receivers on board six FORMOSAT-3/COSMIC low Earth orbit (LEO) satellites and selected two-hundred GPS tracking receivers stationed on the ground (COSMIC stands for Constellation Observing System for Meteorology, Ionosphere, and Climate). Descriptions of the FORMOSAT-3/COSMIC mission are discussed elsewhere in this special issue. We would like to point out that the volume of ionospheric measurements made by the COSMIC satellites is unprecedented. This is due not only to the number of satellites but also the receiver technology that allows for tracking occulting GPS signals in both setting and rising directions with four antennas. The volume and coverage of occultation data collected by the COSMIC satellites make this study possible because the required measurements above oceans and in near horizontal directions are otherwise not available or very coarsely distributed. GAIM-related technical details are referred to the above listed references and a brief introduction is given in the next section. A description of the data used for assimilative modeling and validation analysis is given in section 3. The modeling results for a geomagnetic storm occurred on 7 August 2006, are presented in section 4 together with 2D data-driven global TEC mapping for the same storm. Discussions are given in section 5 to address possible space weather electrodynamical processes responsible for the ionospheric disturbances that are shown in the assimilative modeling results. A summary and conclusions are offered at the end.

\section{GLOBAL ASSIMILATIVE IONOSPHERIC MODEL}

GAIM is built upon a first-principles forward ionospheric model and incorporates a suite of optimization techniques. The forward model numerically solves for ion and electron densities through the continuity and momentum equations of hydrodynamics for individual ions in the following approximate forms:

$$
\begin{aligned}
& \frac{\partial n_{i}}{\partial t}+\nabla \cdot\left[n_{i}\left(\mathbf{v}_{i \perp}+\mathbf{v}_{i \|}\right)\right]=P_{i}-L_{i} \\
& \mathbf{v}_{i \perp}=\frac{\mathbf{E} \times \mathbf{B}}{B^{2}}+\frac{1}{\Omega_{i}} \sum_{j} v_{i j}\left(\mathbf{v}_{j \perp}-\mathbf{v}_{i \perp}\right) \times \mathbf{b} \\
& \mathbf{v}_{i \|}=\frac{1}{m_{i} \sum_{j} v_{i j}}\left[-\frac{k}{n_{i}} \nabla_{\|}\left(n_{i} T_{i}+n_{e} T_{e}\right)+m_{i} \mathbf{g}_{\|}+m_{i} \sum_{j} v_{i j} \mathbf{v}_{j \|}\right]
\end{aligned}
$$

where the subscripts $i$ and $j$ denote the $i$ th and $j$ th ion species while $j$ also denotes neutrals, and $e$ denotes electrons. The variables and constants for $i$ th ion are listed as follows: 
$n_{i} \quad$ volume density

$\mathbf{v}_{i \perp, \|}$ vector velocity perpendicular and parallel to the magnetic field line, respectively

$P_{i} \quad$ production rate

$L_{i} \quad$ loss rate

$m_{\mathrm{i}}$ mass

$T_{i, e}$ ion and electron temperature

$k$ Boltzmann's constant

E vector electric field

B vector magnetic field

$\Omega_{i}$ ion gyro-frequency

$v_{i j} \quad$ collision frequency between species $i$ and $j$, including ion-neutral collisions

b unit vector along the magnetic field line

g gravitational acceleration

The electron density is obtained by the sum of densities for all individual ions, i.e., $n_{e}=\sum_{j} n_{i j}$. Equations (2) and (3) are derived from a combination of ion and electron momentum equations by neglecting the inertial term and relatively small forcing terms. In the $\mathrm{F}$ region ionosphere, where most electrons reside, the second term in Eq. (2) can be neglected since the collision frequencies are much smaller than the ion gyro-frequency. For this analysis only atomic oxygen ions $\left(\mathrm{O}^{+}\right)$are included in the model since the species is the dominant one in the F region, and thus $\mathbf{v}_{j \|}$ in the last term of Eq. (3) reduces to the neutral wind velocity parallel to $\mathbf{B}$. The ion production rate is determined by the photoionization due to absorption of solar EUV radiation and energy deposition of auroral particle precipitation in the thermosphere. The $\mathrm{O}^{+}$ion loss is primarily attributed to the chemical reactions of charge exchange between ions and neutrals. Dynamical processes in the momentum equation for $\mathrm{O}^{+}$ions include convection and diffusion that are controlled by the pressure gradient, gravitation (g), the Lorentz force, and collision between $\mathrm{O}^{+}$ions and neutral particles. GAIM uses well-developed empirical models of various physics forcing parameters for solar EUV irradiance spectrum, thermospheric densities and wind, electric field, and electron energy precipitation flux. GAIM is constructed in an Eulerian 3-dimensional (3D) geomagnetic frame. Our present model adopts a grid following the dipole geomagnetic field configuration, with options setting the frame in a dipole, tilted dipole, or eccentric tilted dipole magnetic filed model. Based on this grid, the partial differential equations are discretized using a finite volume scheme, and the ion state is solved forward in time using a hybrid explicit-implicit time integration scheme. The GAIM physics model is driven by several empirical models that characterize the climatology of solar EUV radiation spectrum, thermospheric densities and composition as well as wind, electric field, and particle precipitation energy. A detailed description of GAIM physics model can be found in
Pi et al. (2003).

GAIM optimization techniques include the recursive Kalman filter technique with approximations (Hajj et al. 2000, 2004; Wang et al. 2004; Pi et al. 2004b; Mandrake et al. 2005) and the 4-dimentional variational (4DVAR) approach with an adjoint method (Rosen et al. 2001; Pi et al. 2003, 2004a; Wang et al. 2004). For this analysis, only the band-limited Kalman filter (BLKF) technique is applied, and a detailed description of the BLKF technique can be found in Hajj et al. (2004). Briefly, the band-limited Kalman filter allows truncating the state covariance matrix such that for a given volume element (voxel), only a subset of the entire set of voxels has non-zero correlation. The non-zero correlation voxels constitute a correlation volume that can be specified with correlation lengths in latitude, longitude, and altitude dimensions. This technique helps to reduce significantly the number of computational operations required to update the state covariance, making it suitable to conduct 3-D modeling with a good spatial resolution even on a global scale without use of supercomputers. A suite of optimization techniques has also been developed for the 4DVAR approach that incorporates the forward model, the model driver parameterization, the adjoint method, and non-linear least squares minimization. The 4DVAR approach has been applied to observation system simulation experiments for estimation of plasma $\mathbf{E} \times \mathbf{B}$ drift and neutral wind at low latitudes by assimilating ground-based GPS TEC measurements (Pi et al. 2003, 2004a). The present study will not involve this approach in order to examine the effectiveness of $\mathrm{BLKF}$ in reconstructing the disturbances of ionospheric state. The characteristics of the state disturbances will then be examined to assess possible responsible dynamical processes.

\section{DATA SOURCES FOR ASSIMILATION}

Assimilative ionospheric modeling becomes attractive and effective as observation systems become available providing numerous measurements on global scales. A good example is the GPS observation system, which consists of not only the constellation of 24 satellites but also networks of hundreds to thousands of ground-based GPS tracking stations distributed globally or regionally. The present global GPS tracking network of International GPS Service (IGS) for geodynamics consists of 340 active stations equipped with geodetic-quality dual-frequency receivers. A modern GPS receiver at each station is capable of tracking 12 to 16 satellites simultaneously, and mostly more than 6 satellites are available in the field of view at any moment.

Recently, this system is significantly augmented by the FORMOSAT-3 mission, the Constellation Observation System for Meteorology, Ionosphere, and Climate (FORMOSAT-3/COSMIC). It is a joint Taiwan and US mission consisting of six LEO spacecraft carrying GPS occultation re- 
ceivers, tri-band beacons, and tiny ionospheric photometers. The GPS occultation receivers on board the spacecraft are based on the BlackJack receivers developed by the Jet Propulsion Laboratory and manufactured by Broad Reach Engineering as the Integrated GPS Occultation Receiver (IGOR). An IGOR receiver can track signals from 4 antennas. On the COSMIC spacecraft, two of these are high gain antennas pointed towards the Earth's limb and two are of lower gain pointing 15 degrees above horizontal. All antennas are aligned along the aft and fore directions. The lower gain (wider field of view) antennas collect data for ionospheric occultation measurements and precise orbit determination. The two high gain antennas observe occultations by the neutral atmosphere. The receiver channels can track C/A, P1, and P2 signals from up to 16 satellites. Similar receivers built by JPL have also flown on a number of other LEO satellites including CHAMP, SAC-C, and GRACE.

The assimilation data sources in our storm study are bias-removed line-of-sight TEC data collected from GPS occultation receivers on board 6 COSMIC satellites in space and from a subset (200) of the IGS stations on the ground. During a day, about 250000 line-of-sight TEC measurements (sampled at a $1 /$ second rate) can be made by each space-borne receiver including setting and rising occulting geometry. However, we are interested in the data coverage within $~ 30$-minute intervals since the GAIM runs for this study use the data within a 12-minute interval to update the ionospheric state at each 12-minute step. Figure 1 gives an overview of data distribution and global ionospheric TEC context, and puts together the following information for such a UT interval on 6 August 2006:

(1) projected locations of the ionospheric piercing points (IPP's) at $450 \mathrm{~km}$ altitude for the ground-based measurements within a 15 -minute interval;

(2) associated vertical TEC values coded in color (vertical TEC is converted from slant measurements using an elevation-dependent obliquity factor to account for the geometric effect);

(3) projected trajectories of GPS occultation tangent points within a 30-minute interval for all 6 COSMIC satellites.

An occultation tangent point (TP) is the closest point to the center of the Earth on an occulting radio link. It should be noted that each occultation radio ray (represented by one TP) passes through a large ionospheric distance in a near horizontal direction. Although some TP tracks look short in the figure, they indicate continuous occultation measurements containing ionospheric information over a large spatial extent. For example, a couple of tracks (red) near $-3^{\circ}$ to $-10^{\circ}$ latitudes end at about $135^{\circ} \mathrm{E}$ longitude, the actual radio rays extend to much larger distances in the southeast and northwest directions. Such space measurements nicely compensate the ground-based measurements, the radio links of the latter intercepting the ionosphere in localized horizontal regions.

Figure 2 gives an example of line-of-sight TEC vs. observation elevation angles measured by the receiver on

08/06/2006 UTC Coverage: grnd 10:15 - 10:29; LEO 10:00 - 10:30

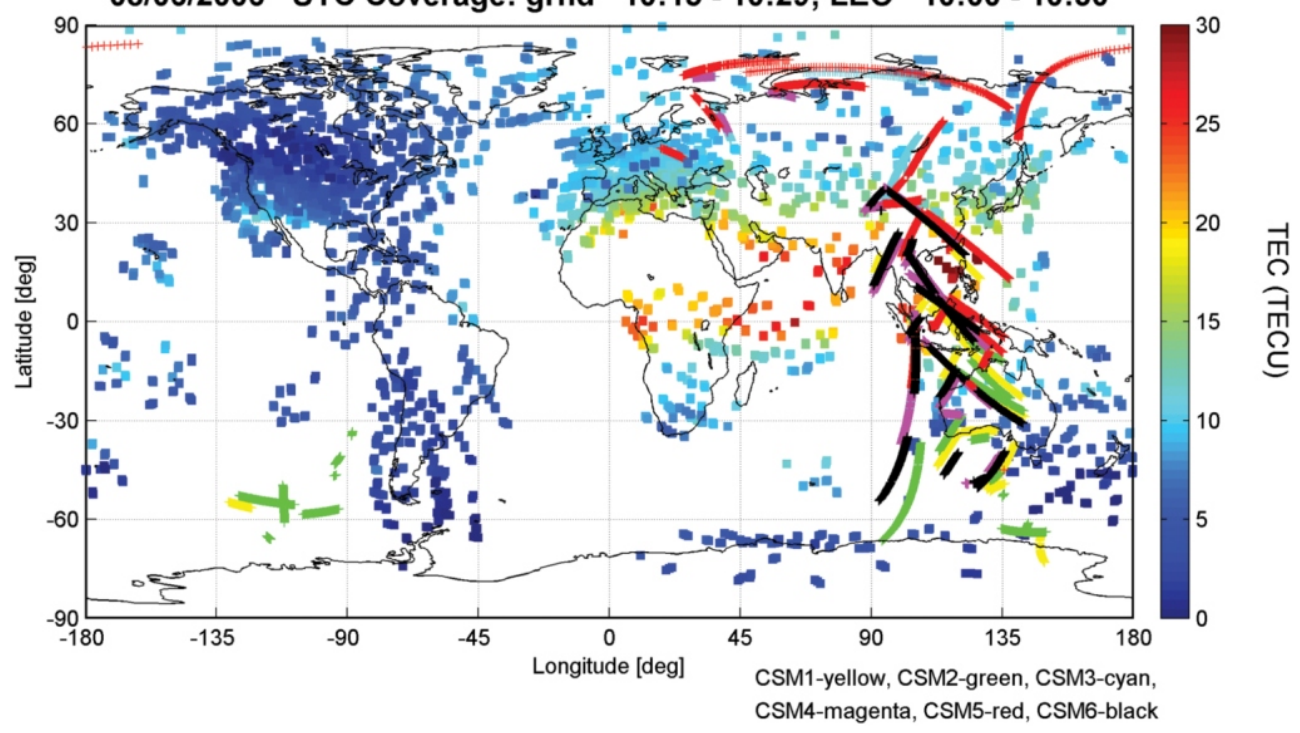

Fig. 1. Plotted is the coverage of GPS observations from space and ground during a short time interval on 6 August 2006, with a global context of the ionosphere under the quiet conditions. Tracks of GPS occultation tangent points (TP's) for six FORMOSAT-3/COSMIC satellites during a 30-minute interval are marked by "+" signs in six colors (black, cyan, green, magenta, red, and yellow). Each TP indicates a line-of-sight measurement of integration of electron density across a large ionospheric region in a near horizontal direction. Projected locations of the ionospheric piercing points at $450 \mathrm{~km}$ altitude for ground-based GPS measurements within a 15-minute interval are marked by squares. The values of ground-based vertical TEC measurements associated with the squares are coded in color to provide a context of the ionospheric conditions. 


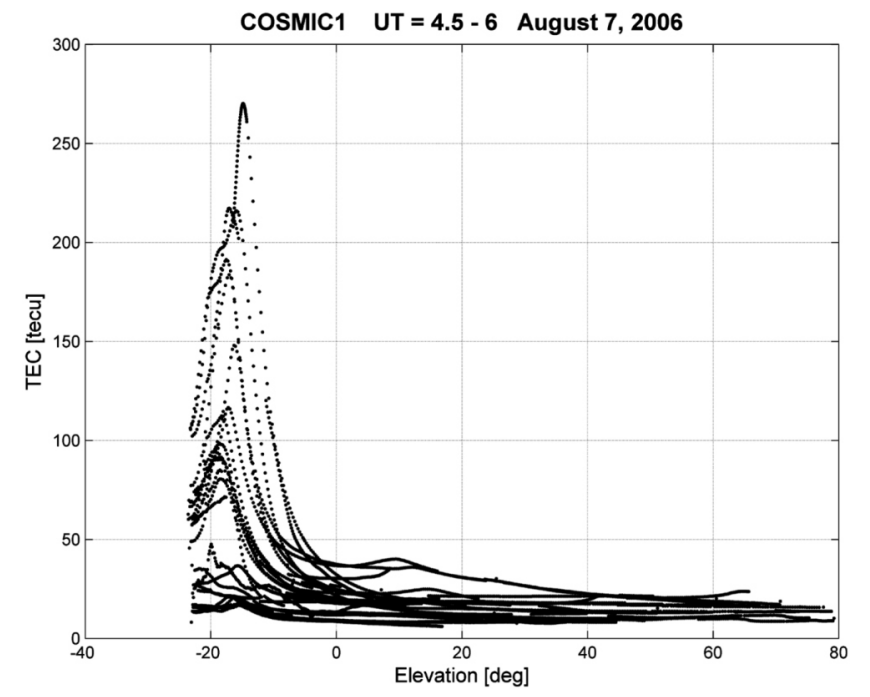

Fig. 2. Line-of-sight TEC vs. observation elevation angles measured by the GPS occultation receiver on board FORMOSAT-3/COSMIC-1 satellite during one orbit revolution on 7 August 2006.

board the COSMIC-1 satellite (CSM1) within one and half hours (one orbit revolution). Multiple data points at each time indicate multiple GPS satellites being tracked simultaneously in different directions by the receiver. The standard IGS data archive includes the GPS carrier phase and pseudorange observables sampled at 30-second intervals. Before performing the data assimilation, the ground data are decimated to 5-minute intervals. The decimation reduces the computation burden and spatial sampling redundancy without affecting the time resolution of the modeling.

The FORMOSAT-3/COSMIC constellation is designed to orbit circularly at about 810 kilometer altitude, with $72^{\circ}$ inclination, in 6 orbital planes spaced $24^{\circ}$ longitudes apart to cover the globe. This final orbit configuration provides an excellent global coverage. When the storm under study occurred, one satellite (CSM5) already reached its nominal altitude at about $810 \mathrm{~km}$ while the other satellites were very close together at orbits ranging from about $525 \mathrm{~km}$ to about $530 \mathrm{~km}$ altitudes since the maneuvers were not completed yet. The orbital geometry of the satellites dictates the observation links so that the radio links from the five lower orbiters to GPS satellites are closely grouped together. These radio links intercepted similar ionospheric regions, while only one satellite (CSM5) provided occultation measurements spanning a larger altitude range. Hence, the spatial coverage of the occultation data within a short time interval provides limited global coverage, even though data from multiple space-borne GPS sensors are available for the study. Thus, our analysis is focused on the regions in which the individual LEO satellites pass over the locations where groundbased measurements are well distributed, so that the region is covered by both space and ground data.

To conduct analysis of storm-time ionospheric distur- bances, data collected for 6 and 7 August 2006, are processed representing quiet and storm conditions, respectively. A similar distribution of ground stations is selected for both days. The occultation data from 6 satellites are available for the quiet day, and from 5 satellites are available for the storm day. The missing space data for the storm day should not significantly affect the modeling results since the missing data would have been collected from one of the five lower orbiters providing nearly redundant measurements with the similar geometry as aforementioned.

\section{ASSIMILATIVE MODELING OF IONOSPEHRIC DISTURBANCES}

The potential of applying assimilative modeling to storm-time ionospheric disturbances for space weather research is appealing since the analyses can be conducted in four dimensions with continuously available GPS data and numerical modeling results. An ionospheric storm is defined as significant disturbances in the ionospheric density distribution on global scales during a geomagnetic storm. Under the conditions of a geomagnetic storm, charged particle precipitation and greatly enhanced electric fields originating in the magnetosphere severely disturb ionization and dynamical processes in the polar region. Enhanced ionospheric currents or plasma convection together with the particle precipitation also interact with the thermosphere via collisions between charged and neutral particles, causing heating and expansion of the thermosphere. The processes result in enhanced equatorward wind and ultimately thermospheric composition changes. The effects extend to lower latitudes and lead to global thermospheric circulation changes. Electric field perturbations due to penetration and the disturbance dynamo, global thermospheric disturbances, and traveling ionospheric disturbances can significantly change the dynamical or transport and chemical processes in the middle- and low-latitude ionosphere, causing ionospheric disturbances on global scales. Numerous studies to understand the coupling of the upper atmospheric regions have been conducted since 1960's, and readers are referred to some early publications (e.g., Rishbeth 1975; Kelley et al. 1979; Prőlss 1980, 1987; Roble et al. 1982; Fejer et al. 1990; Mendillo et al. 1992; Pi et al. 2000). However, modeling of the storm-time ionospheric disturbances is still a challenging topic today due to the complexity of the global coupling system.

The geomagnetic storm under study occurred on $7 \mathrm{Au}-$ gust 2006. Figure 3 shows the geomagnetic $K_{\mathrm{p}}$, AU-AL, and SYM-H (essentially 1-minute resolution $D_{\text {st }}$ ) indices from 5 through 9 August ( $K_{\mathrm{p}}$ covers additional days). The initial phase of the storm started at the beginning of 7 August. The magnetic disturbances reached maximum (level $6^{-}$) between $0900-1200$ UT and then progressed into the recovery phase. To view the global context of ionospheric distur- 

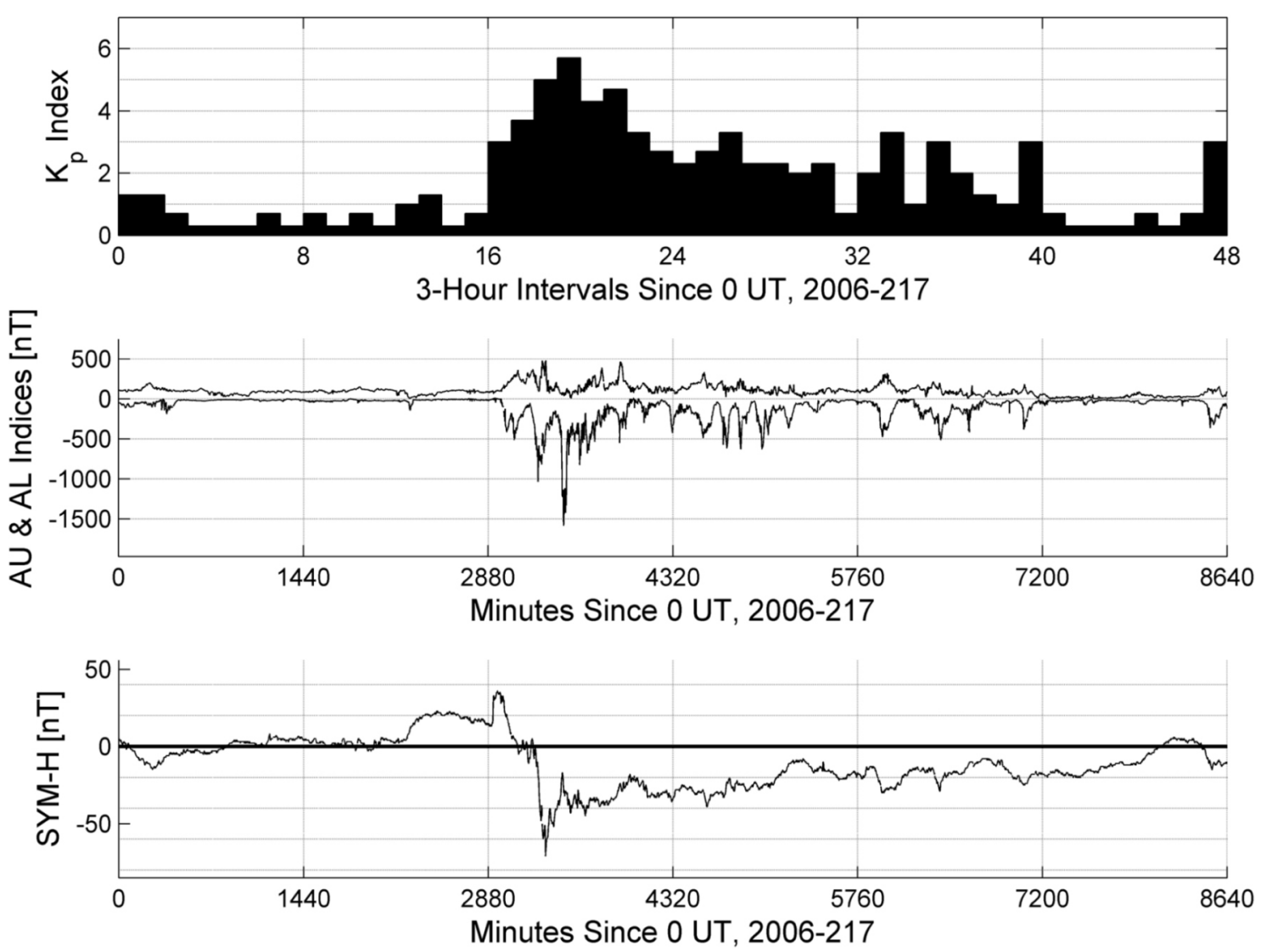

Fig. 3. The geomagnetic $K_{\mathrm{p}}$, AU-AL, and SYM-H indices around and during a geomagnetic storm occurred on 7 August 2006 (DOY=219).

bances under this storm, 2D GIM for vertical TEC is examined first. Note that GIM is a technique that converts slant TEC derived from the GPS observables to vertical, and maps vertical TEC on a global sun-fixed and magnetic grid (e.g., Lu et al. 1998; Mannucci et al. 1998; Iijima et al. 1999). The mapping technique initializes global TEC values using an empirical ionospheric model, and updates the TEC value on each grid point using a Kalman filter and measurements available at and near the corresponding local time and magnetic latitude. Such mapping warrants that TEC values on most grid points are updated within a period of a few hours even though the data coverage is poor at Earth-fixed locations above oceans. Mapping in the sun-fixed geomagnetic grid produces good accuracy by accounting for local time and geomagnetic control of ionospheric processes. The technique is proven very effective under quiet conditions through intensive statistical comparisons with the TOPEX ocean altimeter data, and the similar statistics also indicate that GIM so derived is a good reference even under disturbed conditions at least in regions where the data coverage is good.

Figures 4a through $\mathrm{f}$ show GIM's and global TEC difference maps (GTDM's) for three UT intervals during 0400 - 0415, $0715-0730$, and 1030 - 1045. A GTDM is generated by differencing the storm-time and quiet-time GIM's for the same UT interval and dividing the difference by the quiettime GIM. In these maps ionospheric disturbances are seen first in the polar regions, stronger in the southern hemisphere (Figs. 4a, b). The stronger effect at high latitudes in the southern hemisphere can be understood as the southern disturbance results in a larger fractional TEC increase compared to the low winter-time background in that hemisphere. When the geomagnetic storm proceeds into the main phase after 6 UT, a TEC enhancement of 60 - 90\% appears at magnetically conjugate locations at low and middle latitudes beyond $\pm 14^{\circ}$ in the East Asia and West Pacific sectors. A dip of about $-50 \%$ in the equatorial region in the Pacific sector (Figs. 4c, d) can also be seen. This feature indicates an enhancement in the equatorial anomaly. The disturbance evolves into greater enhancement later seen in extended dayside regions at low and middle latitudes as shown in Figs. 4e and $\mathrm{f}$.

To study disturbance details particularly in altitude and latitude dimensions, the four-dimensional GAIM is run with the BLKF technique assimilating the GPS data. In assimilative modeling, the GAIM physics model is first run to estimate an initial state (electron density) for the subsequent data assimilation run. The physics model then propagates 
(a)

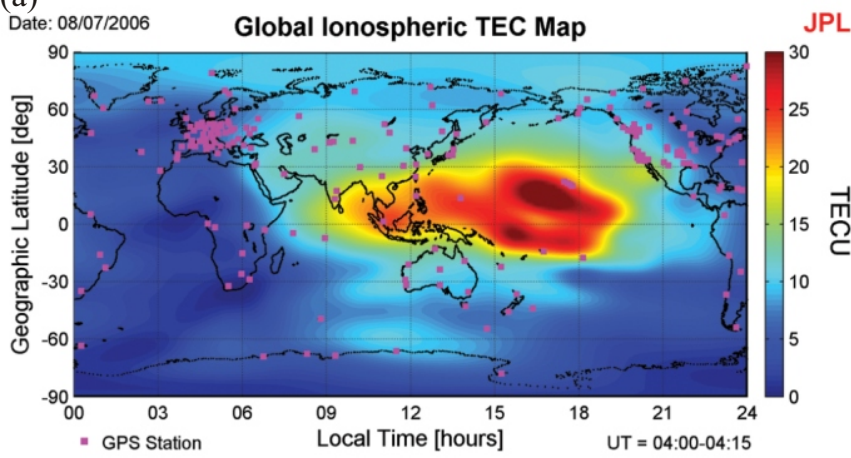

(c)

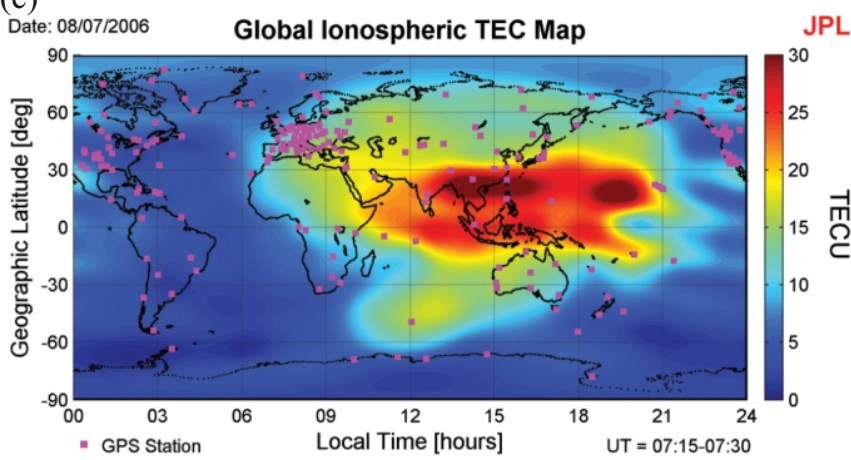

(e)

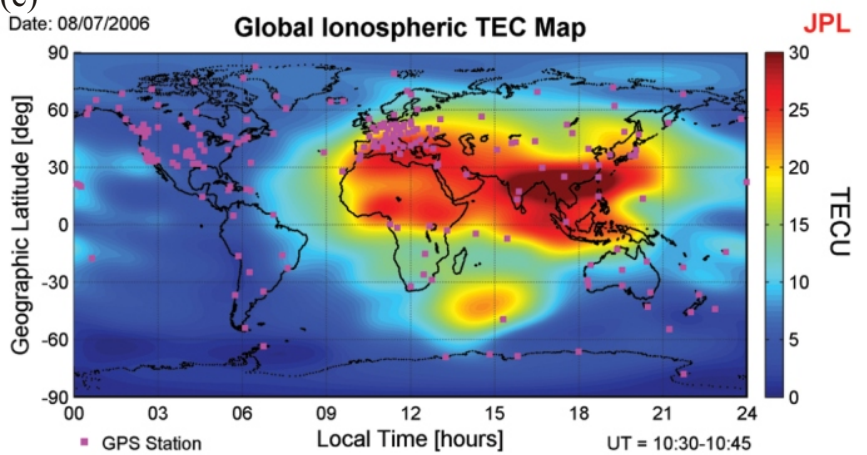

(b)

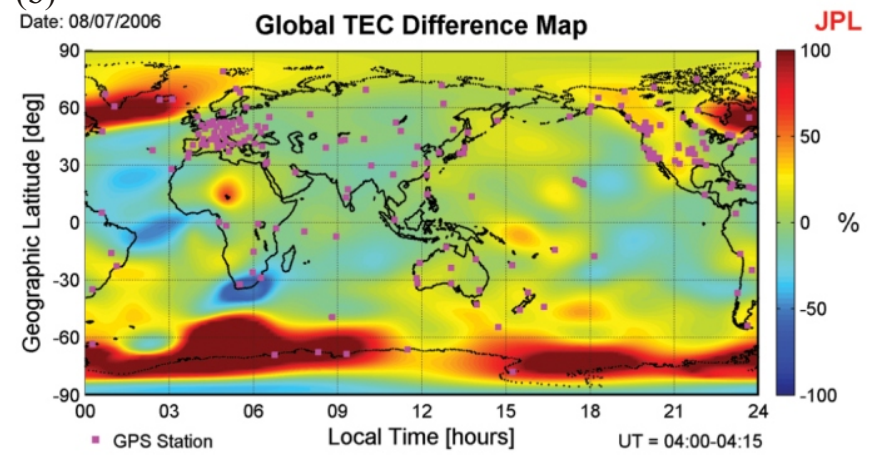

(d)

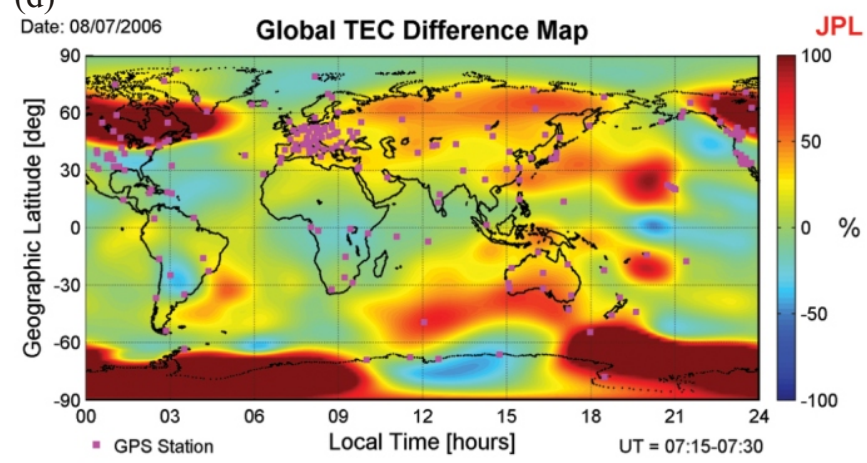

(f)

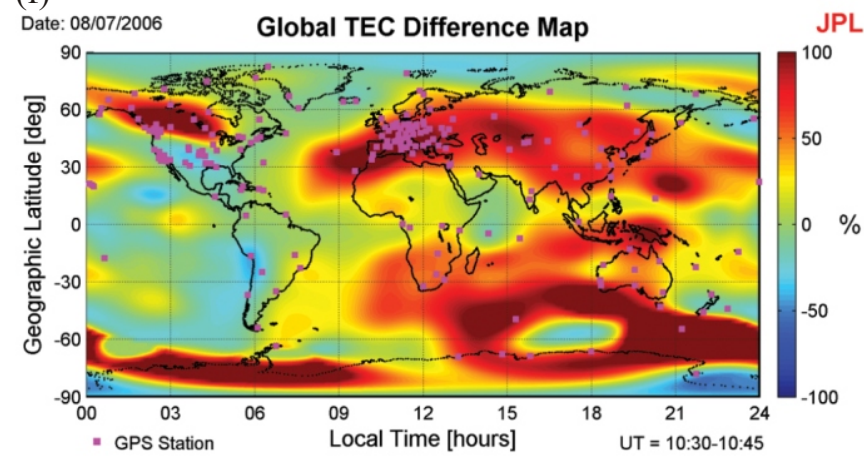

Fig. 4. Plotted are global ionospheric TEC maps [left column, (a), (c), and (e) from top to bottom] and TEC difference maps [right column, (b), (d), and (f) from top to bottom], which are derived using GPS data collected from 200 ground stations during three UT intervals on the storm day 7 August 2006. The TEC difference maps are obtained by differencing the TEC maps between the storm day and quiet day (6 August 2007) for the same UT intervals.

the state to the desired epoch by the state transition matrix with the empirical model drivers. The data assimilation updates the state using the data within the corresponding UT interval. The updated state is then used as the new initial condition for the state transition to the next time step, and the data assimilation cycle repeats with data for the new time interval. In the BLKF process applied to this study, the data assimilation only updates the ionospheric state. The highlatitude physics processes (convection and particle precipitation) in GAIM are switched off and the physics model drivers are kept the same as the empirical drivers, i.e., they are not adjusted as in our 4DVAR experiments. The final output of the modeling is the global ionospheric state (electron densities) at every 12 -minute UT on a $3^{\circ} \times 10^{\circ} \times 10 \mathrm{~km}$ geographic grid (latitude $\times$ longitude $\times$ altitude, converted and interpolated from the geomagnetic grid which is set coarser in the altitude dimension). The 12-minute time step is selected to include enough data to update the modeled state effectively. It is arguable whether this is ideal for modeling storms when high-latitude space weather inputs can change rapidly. Nevertheless the time step allows the model to capture major variations at middle and low latitudes, which is the current focus.

Independent vertical TEC measurements made using the Jason-1 dual-frequency ocean altimeter are compared with the results of both climatological and assimilative modeling as a validation. The top panel of Fig. 5 shows a comparison of TEC between the Jason-1 measurements, GAIM, 


\section{8/07/2006}
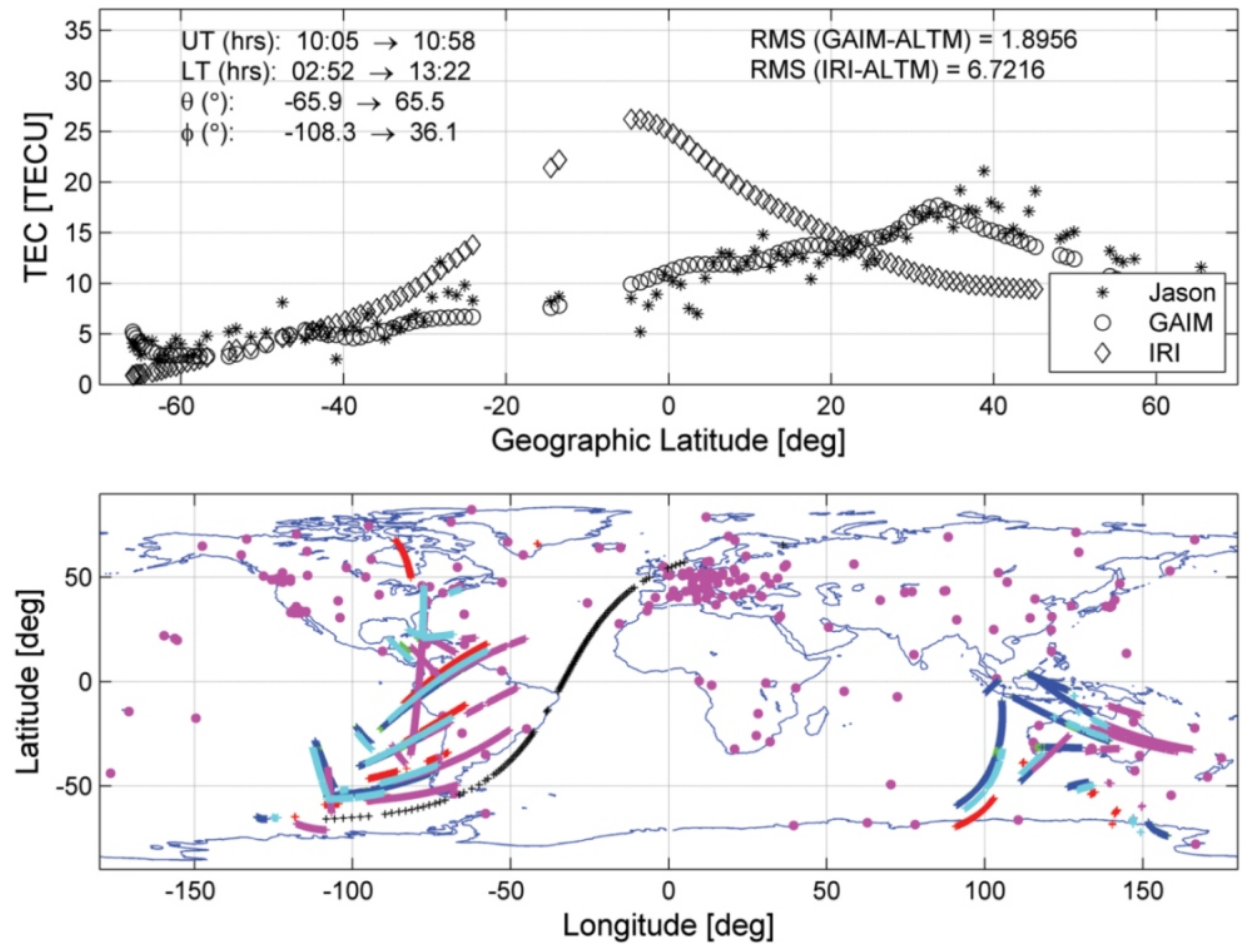

Fig. 5. Top panel: A result of GAIM data assimilation run for the storm conditions on 7 August 2006, is compared with the vertical TEC measured by the Jason-1 ocean altimeter and modeled by the IRI empirical ionospheric model for a Jason-1 satellite pass. Bottom panel: the ground tracks of GPS occultation tangent points for five FORMOSAT-3/COSMIC satellites (marked in blue, cyan, green, magenta, and red colors) are plotted for the same time interval as in the top panel with the Jason-1 orbit track (black) and the locations of GPS ground stations (magenta dots).

and the International Reference Ionosphere (IRI) empirical model under the storm conditions along a Jason-1 orbit pass. The bottom panel of Fig. 5 provides a reference data coverage as in the similar plot as Fig. 1 except that the IPP's and associated TEC values are replaced by the locations of ground stations. Figure 6 shows a histogram of TEC difference for GAIM climatology, GAIM data assimilation, and the IRI empirical model with respect to the altimeter measurements along all Jason-1 orbital tracks for the entire storm day. The comparisons indicate that under the disturbed conditions, the assimilative modeling with space and ground GPS data approaches the weather conditions even though the comparisons are performed for regions above oceans (to follow the Jason-1 tracks) where there is a lack of ground data coverage.

We now turn to examination of the disturbed equatorial anomaly in the altitude and latitude dimensions. The examination is focused on (1) the changes in the ionospheric state relative to the quiet-time reference, (2) the ionospheric state at 1024 UT when the disturbance is significant and well developed, and (3) the East Asia region where the coverage of both space and ground data is good for both quiet and storm days at the time of interest. Figure 1 shown in the previous section gives the data coverage during $1000-1030$ UT on the quiet day (6 August). Figure 7 shows a similar spatial

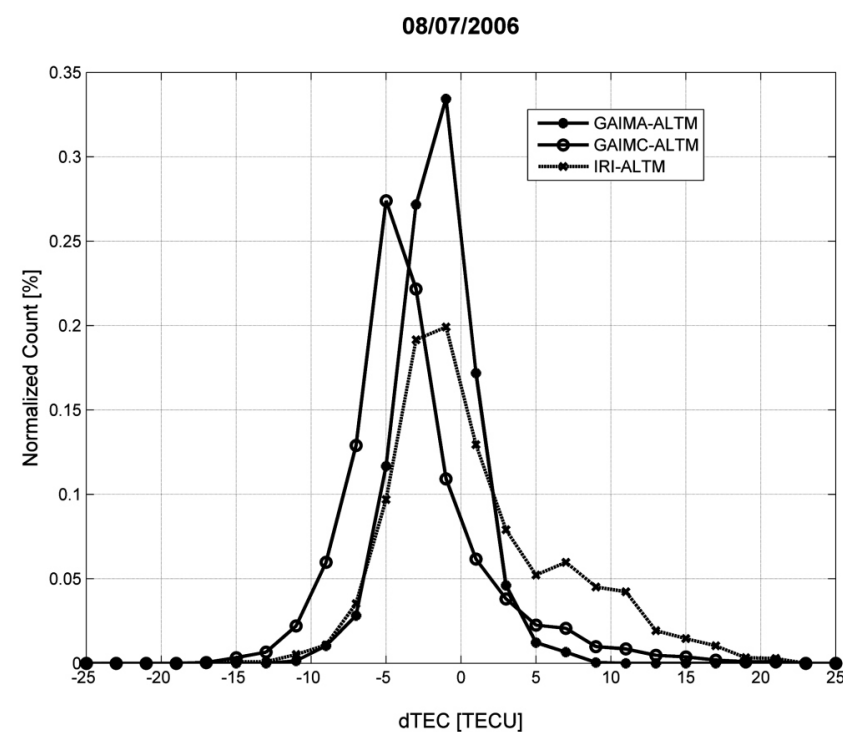

Fig. 6. Histogram of TEC difference resulted from GAIM physics model (GAIMC-ALTM), GAIM data assimilation run (GAIMA-ALTM), and IRI predictions (IRI-ALTM), with respect to the Jason-1 ocean altimeter measurements (ALTM) along all Jason-1 orbital tracks for the entire storm day on 7 August 2006. 


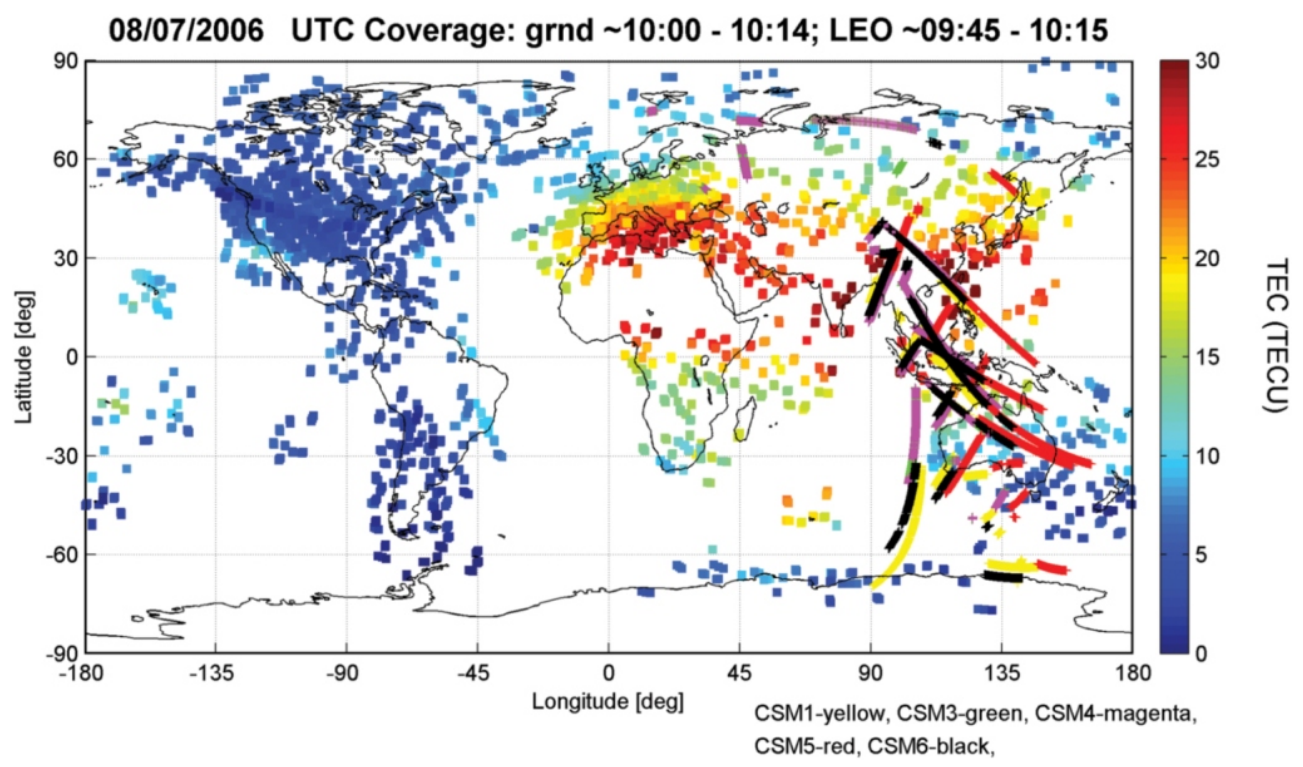

Fig. 7. A coverage plot as Fig. 1 for a comparable UT interval but on the storm day.

coverage on the storm day (7 August), though the time is 15 minutes earlier. The small time difference is due to the COSMIC orbit periods that result in slight changes in the GPS occultation geometry relative to the ground between the two consecutive days for the same UT.

The assimilation results for electron densities are shown in contour plots (altitude vs. latitude) at $125^{\circ}$ longitude in Fig. 8 (left column) for the quiet and storm days, respectively. The percentage density difference $\left[\left(n_{e, \text { storm }}-n_{e, \text { quiet }}\right) / n_{e, \text { quiet }}\right.$ $\times 100]$ and vertical profiles at the equator are also provided in the right column. Significant increases ( $150-200 \%)$ of electron density at low latitudes in this longitude sector during the storm are seen (upper right panel) at magnetic conjugate locations off the magnetic equator (at about $8^{\circ} \mathrm{N}$ geographic latitude) between 200 to $600 \mathrm{~km}$ altitudes. The enhancement feature is tilted towards higher altitudes at lower latitudes. On the other hand, electron density decreases at and near the magnetic equator compared with the quiet-time reference. In addition, the ionospheric layer is lifted near the equator (right panels), and the height of the $\mathrm{F}$ layer peak density or $h_{\mathrm{m}} \mathrm{F}_{2}$ is about $100 \mathrm{~km}$ higher than its quiet-time reference. These disturbance characteristics at low latitudes suggest an enhanced fountain effect, in which the equatorial ionospheric plasma is lifted and then diffuses down to lower altitudes and higher latitudes along the magnetic field lines to form the enhanced equatorial anomaly features.

We now recall Figs. 4e and $f$, in which the enhanced equatorial anomaly revealed in the longitude and latitude dimensions is seen not only in the dusk sector but also in the afternoon and later evening sectors. It is interesting to see whether the similar altitude-latitude feature seen near the dusk (1844 LT) extends to later local times as the TEC mapping indicates. Hence the modeling results are examined fur- ther at $135^{\circ}$ longitude as shown in Fig. 9 corresponding to 1924 LT at the same UT. The similar enhanced equatorial features indeed appear at this longitude or local time sector too. A difference is that the modeling results for both quiet and disturbed conditions exhibit even higher $\mathrm{F}$ layer at the later local time, noting that $h_{\mathrm{m}} \mathrm{F}_{2}$ reaches $\sim 450 \mathrm{~km}$ on the quiet day and $\sim 530 \mathrm{~km}$ on the storm day. Such a disturbance after dusk may lead to triggering of the plasma RayleighTaylor instability and thus formation of ionospheric irregularities at low latitudes, if the conditions overwhelm possible suppressing mechanisms. Further study of possible irregularity activity during this storm is beyond the scope of this paper and is not pursued here.

\section{DISCUSSIONS}

The 4D modeling of electron density variations, particularly in altitude-latitude dimensions, benefit from two major factors: (1) assimilating GPS data into GAIM brings the model results close to the actual ionospheric weather; (2) assimilating COSMIC GPS occultation data in addition to ground-based GPS observations into GAIM helps to improve the model accuracy by providing measurements over oceans and observation links in near horizontal directions. The importance of the second point can be understood by considering an ideal geometry for tomographic imaging, in which measurements in all directions (either 2D or 3D) are required to achieve high accuracy. The COSMIC GPS occultation data compensate for the limited range of observation links available from ground-based GPS observations.

The ionospheric features in 2D TEC and particularly 3D density of the assimilative modeling results all indicate an 

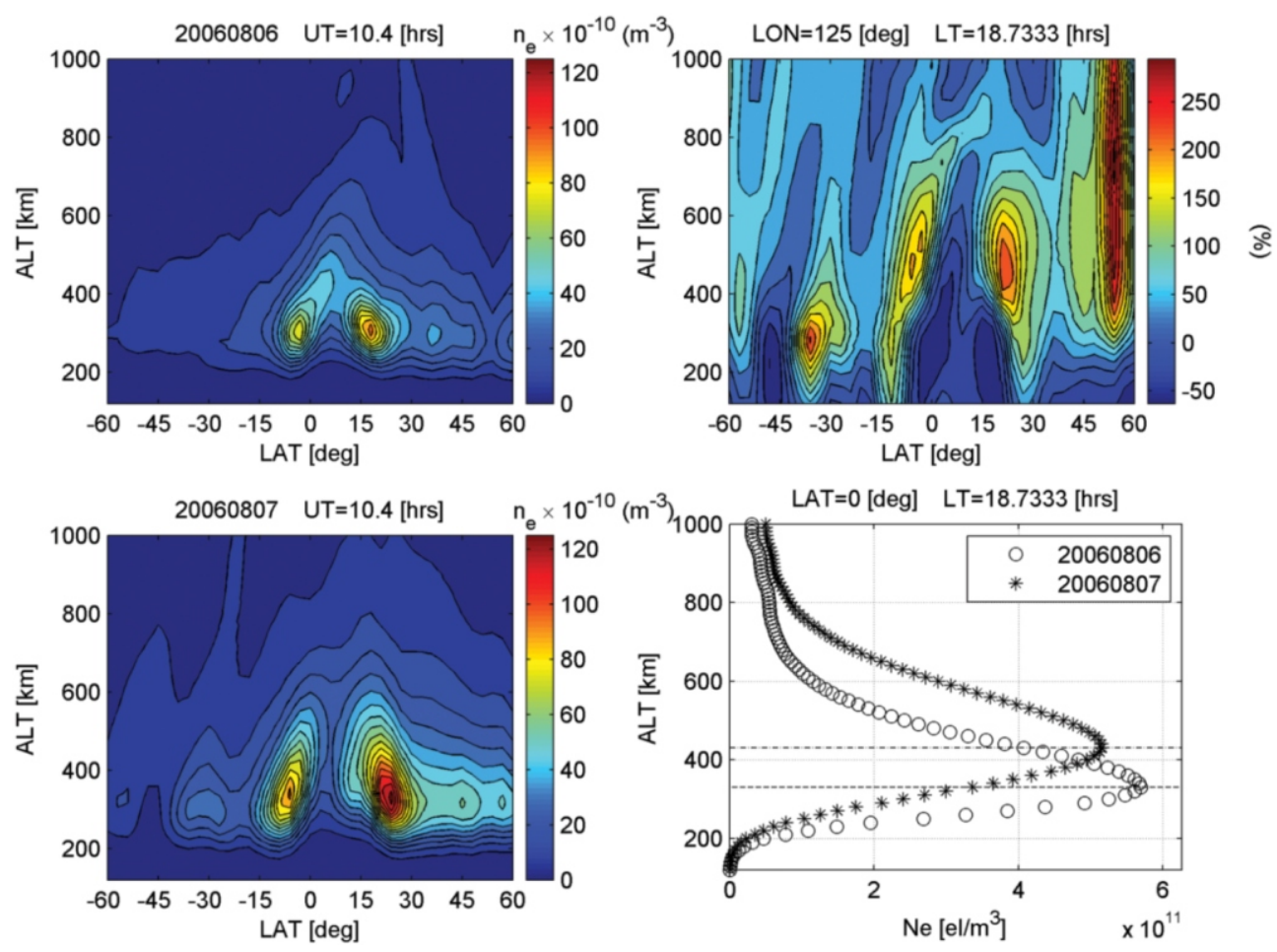

Fig. 8. Electron density contours showing the assimilative modeling results in altitude vs. latitude dimensions at $125^{\circ}$ longitude, for the quiet day ( 6 August 2006; upper left), storm day (7 August 2006; lower left), and percentage difference between the disturbed and quiet state (upper right). A comparison of sample electron density profiles at the equator is also provided in the lower-right panel. The corresponding local time is 1844 for this longitude. The storm-time disturbance shows clear features of equatorial anomaly enhancement that must be driven by an enhancement of eastward electric field at low latitudes.
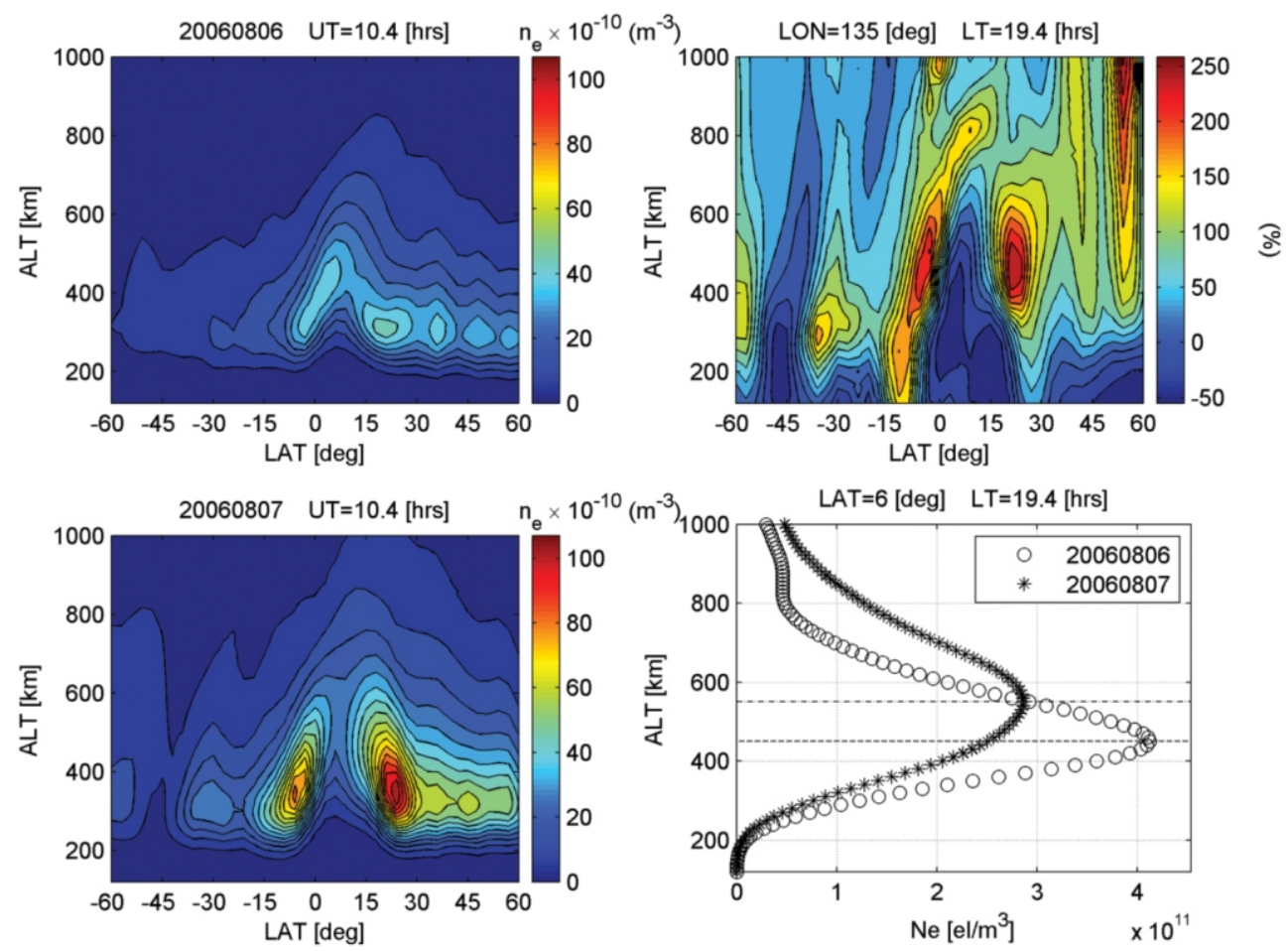

Fig. 9. Similar plots as Fig. 8 during the same UT interval on the storm day but for $1924 \mathrm{LT}$ at $135^{\circ}$ longitude. 
enhancement in the equatorial anomaly. Note that we are focused on the storm-time changes in the equatorial anomaly that are revealed in this study instead of the equatorial anomaly itself. The equatorial anomaly phenomenon was discovered about 60 years ago (Appleton 1946). The characteristics of its variation are studied here to distinguish perturbations of dynamical sources during the storm. The perturbed equatorial anomaly or fountain effect must be driven by an enhancement of eastward electric field during the storm. This identification enables us to distinguish the electric field perturbation from other perturbation sources such as wind or composition changes without ambiguity.

Recalling the references cited in the beginning of last section, several major electrodynamical perturbations during storms causing disturbances in the middle and low latitude ionosphere are worth discussion: electric field penetration of the magnetospheric origin, shielding and overshielding effects, and electric field perturbations caused by wind dynamo disturbances. The classic picture of electric field penetration is that an eastward enhancement on dayside and westward enhancement on nightside can occur due to the enhancement of dawn-to-dusk electric potential difference, which is mapped down from the magnetosphere over the polar cap (e.g., Kelley et al. 1979). The shielding of the magnetospheric electric field becomes effective as the ring current region is populated with energetic particles when the storm main phase evolves. Further, when the shielding becomes effective, the remnant polarization electric field built in reaction to the penetration effect would then cause electric field perturbation in the opposite direction. These processes may occur within in a short time scale on the order of an hour or so (Fejer et al. 1990). The ionospheric response to space weather effects studied here seems to indicate that the penetration scenario fits the conjugate enhancement in the dayside ionosphere at low latitudes seen in TEC maps before 0730 UT (Fig. 6, right-middle panel), which can be caused by an eastward electric field penetration driving an enhanced equatorial fountain effect. However, there is no apparent evidence showing overshielding effect during a few hours after the enhanced fountain effect.

Examining the AU-AL and SYM-H data as done in some previous studies (e.g., Kelley et al. 1979; Pi et al. 2000), we also notice that after GIM shows an enhanced equatorial anomaly at and before 0715 UT (Fig. 4d), there is another enhancement in the auroral electrojet and ring current after $\sim 0930$ UT following the storm main phase between 0600 - 0930 UT. Following these activities, assimilative modeling shows a clear enhancement in $3 \mathrm{D}$ pictures of the equatorial anomaly around dusk and during evening (Figs. 8 and 9), which again is likely caused by an enhanced eastward electric field. The origin of this perturbation becomes interesting since it doesn't seem to fit the simplified picture of penetration of dawn-to-dusk electric field over the polar cap, which would cause little zonal electric field perturbations at dusk due to its orientation. A plausible explanation is the disturbance wind dynamo that can also cause major electrodynamical perturbations during storms. Characteristics associated with either electric field penetration or disturbance dynamo in the dusk sector deserve in depth study that is beyond the scope of this work. Again, understanding the enhancement of eastward electric field during dusk and evening hours is a very interesting topic since it affects the triggering and development of the plasma Rayleigh-Taylor instability in the lowlatitude ionosphere.

\section{SUMMARY AND CONCLUSIONS}

The global assimilative ionospheric model has been applied to a study of ionospheric storm conditions for the first time. The study becomes possible largely due to the FORMOSAT-3/COSMIC mission which provides an unprecedented volume of GPS occultation data. The COSMIC GPS occultation data fill large coverage gaps over oceans and provide observation links in near horizontal directions. The latter compensates the geometry of ground-based GPS observation links such that the observation system geometry becomes tomographically optimal. The significantly improved data coverage and observation geometry helps to improve the accuracy of GAIM 4D ionospheric imaging. In this study, GPS data collected from six FORMOSAT-3/ COSMIC satellites and two hundred globally distributed IGS stations are assimilated into GAIM for modeling the quiet-time and storm-time ionosphere on 6 and 7 August 2006 , respectively. The investigation is focused on ionospheric disturbances under solar minimum conditions at low latitudes in the East Asia sector, where the good coverage of both space and ground data allows detailed analysis during dusk and evening.

The assimilative modeling of both quiet and storm conditions allows for the investigation of ionospheric disturbances compared with a quiet reference. The results of modeling with the band-limited Kalman filter technique show a significant enhancement of the equatorial anomaly during the storm at the dusk and evening hours in the East Asia sector. It should be pointed out that the GAIM runs conducted for this study do not adjust model drivers using assimilated GPS data. The high-latitude physics processes (convection and particle precipitation) are switched off, and the empirical electric field at low latitudes is kept the same in the physics model. Thermospheric changes due to the MSIS and HWM empirical models do not cause the disturbed equatorial anomaly seen in the model results. It is the results of data assimilation with the BLKF technique that present a pronounced enhancement feature in the plasma fountain effect, including reduced electron density and lifted $\mathrm{F}$ layer in the equatorial ionosphere, enhanced electron density at the magnetically conjugate anomaly latitudes, and tilted feature 
of density increase towards higher altitudes at lower latitudes.

The equatorial anomaly is a well-known phenomenon discovered by Edward V. Appleton more than 60 years ago (Appleton 1946). Although there were modeling and observation studies in the past about the phenomenon, it is the storm-time changes that are investigated here instead of the equatorial anomaly itself. GAIM assimilating GPS data particularly the FORMOSAT-3/COSMIC data makes it possible to investigate the storm-time disturbances in four dimensions realistically, particularly in the altitude dimension. It is demonstrated in this study that the 4D assimilative modeling even for state variations only enables us to distinguish the storm-time electric field perturbations from other sources. This shows great potential of assimilative modeling in future studies considering the difficulty of separating various driving sources without direct measurements of those drivers.

Predicting perturbations of the driving force of the equatorial anomaly, i.e., zonal electron field, during a geomagnetic storm is still a research topic today. Our analysis of the ionospheric response to the space weather effects during this storm indicates that electric field penetration of magnetospheric origin during the early phase of the storm is likely the cause of enhanced eastward electric field and enhancement of equatorial anomaly on dayside. In addition, an enhanced equatorial anomaly is also seen during dusk and evening hours during the storm main phase. Whether the zonal electric field perturbation at dusk is due to the penetration effect or a wind dynamo perturbation and their effectiveness at different local times deserve further study. The enhanced eastward electric field during dusk and evening hours is an interesting topic since it affects triggering and development of the plasma Rayleigh-Taylor instability at low latitudes. For these outstanding research topics, the assimilative modeling with the existing GPS data now makes it possible to conduct related studies. It is expected that such studies can be performed to even larger scales simultaneously in various regions as all COSMIC satellites reach their final orbits.

Ackowledgements The authors thank James F. Zumberge, Thomas K. Meehan, and Lawrence E. Young at the Jet Propulsion Laboratory for their help to this work. Special thanks to Frank Cheng, Charles Lin, Yen-Hsyang Chu, and Han-Tzong Su at the National Space Organization, the National Central University, and the National Cheng-Kung University of Taiwan, respectively, for the discussions of this work. The authors are also grateful to the National Space Organization (Republic of China) and the University Corporation for Atmospheric Research (USA) for making the FORMOSAT-3/COSMIC data available to worldwide science communities. The research conducted at the Jet Propulsion Laboratory, California Institute of Technology, is under a contract with the National Aeronautics and Space Administration (USA).

\section{REFERENCES}

Angling, M. J. and B. Khattatov, 2006: Comparative study of two assimilative models of the ionosphere. Radio Sci., 41, doi: 10.1029/2005RS003372. [Link]

Appleton, E. V., 1946: Two anomalies in the ionosphere. $\mathrm{Na}$ ture, 157, 691-691, doi: 10.1038/157691a0. [Link]

Bust, G. S. and G. Crowley, 2007: Tracking of polar cap patches using data assimilation. J. Geophys. Res., 112, A05307, doi: 10.1029/2005JA011597. [Link]

Bust, G. S., G. Crowley, T. W. Garner, T. L. Gaussiran II, R. W. Meggs, C. N. Mitchell, P. S. J. Spencer, P. Yin, and B. Zapfe, 2007: Four-dimensional GPS imaging of space weather storms. Space Weather, 5, S02003, doi: 10.1029/ 2006SW000237. [Link]

Fejer, B. G., R. W. Spiro, R. A. Wolf, and J. C. Foster, 1990: Latitudinal variations of perturbation electric fields during magnetically disturbed periods: 1986 SUNDIAL observations and model results. Ann., Geophys., 8, 441.

Garcia-Fernandez, M., A. Saito, J. M. Juan, and T. Tsuda, 2005: Three-dimensional estimation of electron density over Japan using the GEONET GPS network combined with SAC-C data and ionosonde measurements. J. Geophys. Res., 110, A11304, doi: 10.1029/2005JA011037. [Link]

Hajj, G. A., L. C. Lee, X. Pi, L. J. Romans, W. S. Schreiner, P. R. Straus, and C. Wang, 2000: COSMIC GPS ionospheric sensing and space weather. Terr. Atmos. Ocean. Sci., 11, 235-272. [Link]

Hajj, G. A, B. D. Wilson, C. Wang, X. Pi, and I. G. Rosen, 2004: Data assimilation of ground GPS total electron content into a physics-based ionospheric model by use of the Kalman filter. Radio Sci., 39, RS1S05, doi: 10.1029/2002 RS002859. [Link]

Hernández-Pajares, M., J. M. Juan, J. Sanz, and J. G. Sole, 1998: Global observation of the ionospheric electronic response to solar events using ground and LEO GPS data. J. Geophy. Res. Space Phys., 103, 20789-20796, doi: 10.1029/98JA01272. [Link]

Iijima, B. A., I. L. Harris, C. M. Ho, U. J. Lindqwister, A. J. Mannucci, X. Pi, M. J. Reyes, L. C. Sparks, and B. D. Wilson, 1999: Automated daily process for global ionospheric total electron content maps and satellite ocean altimeter ionospheric calibration based on Global Positioning System data. J. Atmos. Sol.-Terr. Phys., 61, 1205-1218, doi: 10.1016/S1364-6826(99)00067-X. [Link]

Jee, G., A. G. Burns, W. Wang, S. C. Solomon, R. W. Schunk, L. Scherliess, D. C. Thompson, J. J. Sojka, and L. Zhu, 2007: Duration of an ionospheric data assimilation initialization of a coupled thermosphere-ionosphere model. Space Weather, 5, S01004, doi: 10.1029/2006SW000250. [Link]

Kelley, M. C., B. G. Fejer, and C. A. Gonzales, 1979: An explanation for anomalous ionospheric electric fields associated 
with a northward turning of the interplanetary magnetic field. Geophys. Res. Lett., 6, 301, doi: 10.1029/GL006i 004p00301. [Link]

Lu, G., X. Pi, A. D. Richmond, and R. C. Roble, 1998: Variations of total electron content during geomagnetic disturbances: A model/observation comparison. Geophy. Res. Lett., 25, 253, doi: 10.1029/97GL03778. [Link]

Mandrake, L., B. Wilson, C. Wang, G. Hajj, A. Mannucci, and X. Pi, 2005: A performance evaluation of the operational Jet Propulsion Laboratory/University of Southern California Global Assimilation Ionospheric Model (JPL/USC GAIM). J. Geophys. Res., 110, doi: 10.1029/2005JA 011170. [Link]

Mannucci, A. J., B. D. Wilson, D. N. Yuan, C. H. Ho, U. J. Lindqwister, and T. F. Runge, 1998: A global mapping technique for GPS-derived ionospheric total electron content measurements. Radio Sci., 33, 565-582, doi: 10.1029/ 97RS02707. [Link]

Mendillo, M., X. Q. He, and H. Rishbeth, 1992: How the effects of winds and electric fields in F2-layer storms vary with latitude and longitude: A theoretical study. Planet. Space Sci., 40, 595-606, doi: 10.1016/0032-0633(92)90001-5. [Link

Mitchell, C. N., I. K. Walker, S. E. Pryse, I. Kersley, I. W. McCrea, and T. B. Jones, 1998: First complementary observations by ionospheric tomography, the EISCAT Svalbard radar and the CUTLASS HF radar. Ann. Geophys., 16, 1519-1522, doi: 10.1007/s00585-998-1519-2. [Link]

Pi, X., M. Mendillo, W. J. Hughes, M. J. Buonsanto, D. P. Sipler, J. Kelly, Q. Zhou, G. Lu, and T. J. Hughes, 2000: Dynamical effects of geomagnetic storms and substorms in the middle latitude ionosphere: An observational campaign. J. Geophys. Res., 105, 7403, doi: 10.1029/1999 JA900460. [Link]

Pi, X., C. Wang, G. A. Hajj, I. G. Rosen, B. D. Wilson, and G. J. Bailey, 2003: Estimation of $\mathrm{E} \times \mathrm{B}$ drift using a global assimilative ionospheric model: An observation system simulation experiment. J. Geophys. Res., 108, 1075-1087, doi: 10.1029/2001JA009235. [Link]

Pi, X., C. Wang, G. A. Hajj, G. Rosen, B. D. Wilson, and A. J. Mannucci, 2004a: Assimilative modeling of low-latitude ionosphere. IEEE Plans, 4, 543- 550.
Pi, X., G. A. Hajj, B. D. Wilson, A. J. Mannucci, A. Komjathy, L. Mandrake, C. Wang, and G. Rosen, 2004b: 3-dimensional assimilative ionospheric modeling for regions of large TEC gradient. Proceedings of the 2004 National Technical Meeting of the Institute of Navigationm, January 26 - 28, 2004, The Catamaran Resort Hotel, San Diego, California, 753-760.

Prőlss, G. W., 1980: Magnetic storm associated perturbations of the upper atmosphere: Recent results obtained by satellite-borne gas analyzers. Rev. Geophys. Space Phys., 18, 183, doi: 10.1029/RG018i001p00183. [Link]

Prőlss, G. W., 1987: Storm-induced changes in the thermospheric composition at middle latitudes. Planet. Space Sci., 35, 807, doi: 10.1016/0032-0633(87)90041-9. [Link]

Rishbeth, H., 1975: F-region storms and thermospheric circulation. J. Atmos. Terr. Phys., 37, 1055-1064, doi: 10.1016/ 0021-9169(75)90013-6. [Link]

Roble, R. G., R. E. Dickson, and E. C. Ridley, 1982: Global circulation and temperature structure of thermosphere with high-latitude plasma convection. J. Geophys. Res., 87, 1599-1614, doi: 10.1029/JA087iA03p01599. [Link]

Rosen, I. G., C. Wang, G. Hajj, X. Pi, and B. Wilson, 2001: An adjoint method based approach to data assimilation for a distributed parameter model for the ionosphere. Proceedings of the $40^{\text {th }}$ IEEE Conference on Decision and Control, Orlando, Florida, Dec. 4-7.

Scherliess, L., R. W. Schunk, J. J. Sojka, and D. C. Thompson, 2004: Development of a physics-based reduced state Kalman filter for the ionosphere. Radio Sci., 39, doi: 10.1029/ 2002RS002797. [Link]

Wang, C., G. A. Hajj, X. Pi, I. G. Rosen, and B. D. Wilson, 2004: Development of the global assimilative ionospheric model. Radio Sci., 39, doi: 10.1029/2002RS002854. [Link]

Yin, P., C. N. Mitchell, P. S. J. Spencer, and J. C. Foster, 2004: Ionospheric electron concentration imaging using GPS over the USA during the storm of July 2000. Geophys. Res. Lett., 31, L12806, doi: 10.1029/2004GL019899. [Link]

Yin, P., C. N. Mitchell, and G. Bust, 2006: Observations of the F region height redistribution in the storm-time ionosphere over Europe and the USA using GPS imaging. Geophys. Res. Lett., 33, L18803, doi: 10.1029/2006GL027125. [Link] 